\title{
Endoscopic findings in upper gastrointestinal bleeding patients at Lacor hospital, northern Uganda
}

\author{
*Alema ON, Martin DO, Okello TR \\ Department of Surgery, Endoscopy unit, Lacor Hospital, Uganda
}

\begin{abstract}
Background: Upper gastrointestinal bleeding (UGIB) is a common emergency medical condition that may require hospitalization and resuscitation, and results in high patient morbidity. Upper gastrointestinal endoscopy is the preferred investigative procedure for UGIB because of its accuracy, low rate of complication, and its potential for therapeutic interventions.

Objective: To determine the endoscopic findings in patients presenting with UGIB and its frequency among these patients according to gender and age in Lacor hospital, northern Uganda.

Methods: The study was carried out at Lacor hospital, located at northern part of Uganda. The record of 224 patients who underwent endoscopy for upper gastrointestinal bleeding over a period of 5 years between January 2006 and December 2010 were retrospectively analyzed.

Results: A total of 224 patients had endoscopy for UGIB which consisted of $113(50.4 \%)$ males and $111(49.6 \%)$ females, and the mean age was 42 years \pm SD 15.88 . The commonest cause of UGIB was esophagealvarices consisting of $40.6 \%$, followed by esophagitis (14.7\%), gastritis (12.6\%) and peptic ulcer disease (duodenal and gastric ulcers) was $6.2 \%$. The malignant conditions (gastric and esophageal cancers) contributed to $2.6 \%$. Other less frequent causes of UGIB were hiatus hernia (1.8), duodenitis $(0.9 \%)$, others-gastric polyp $(0.4 \%)$. Normal endoscopic finding was $16.1 \%$ in patients who had UGIB

Conclusions: Esophageal varices are the commonest cause of upper gastrointestinal bleeding in this environment as compared to the west which is mainly peptic ulcer disease.

Key words: Endoscopy, upper gastrointestinal bleeding, Lacor hospital.

African Health Sciences 2012; (4): 518 - 521 http://dx.doi.org/10.4314/ahs.v12i4.19
\end{abstract}

\section{Introduction}

Upper gastrointestinal bleeding (UGIB) is a common emergency medical condition that may require hospitalization and resuscitation, and results in high patient morbidity ${ }^{1}$.In a reported study the annual incidence of UGIB is approximately 100 cases per 100,000 populations. Bleeding from the upper gastro intestinal tract is approximately 4 times as common as bleeding from the lower gastro intestinal tract with mortality rates from UGIB are $6-10 \%$ overall $^{2}$.

A variety of conditions can cause UGIB, and bleeding from peptic ulcer remains the commonest cause accounting for approximately $50 \%$, of the cases, followed by esophageal varices $(14 \%)$,mallory-weis tears $(5 \%)$. Other causes include tumors, erosions and arteriovenous malformations ${ }^{3}$.The initial evaluation of these patients with UGIB for hemodynamic stability is essential. Early aggressive

\section{*Corresponding author:}

Alema Onira Nelson

Department of Surgery, Endoscopy unit

Lacor Hospital, Uganda

E-mail: nelsonalema@yahoo.com resuscitation of a hemodynamically unstable patient can reduce mortality in acute $\mathrm{UGIB}^{4}$

The effective treatment depends on identification of the source of the bleeding and expeditious administration of therapy ${ }^{5}$. Upper gastrointestinal endoscopy is the preferred investigative procedure for UGIB because of its accuracy, low rate of complication, and its potential also for therapeutic interventions 3,6

This study was carried out to evaluate the endoscopic findings in patients presenting with UGIB and its frequency among these patients according to gender and age.

\section{Methods}

This retrospective analysis included all patients referred to endoscopy unit from both the hospital's own units and surrounding hospitals with history of upper gastrointestinal bleeding between January 2006 and December 2010. A total of 224 patients had endoscopy for UGIB and the records were reviewed. The endoscopy was performed in the endoscopic room under lignocaine guggle by one 
of the three surgeons experienced in endoscopy. Excluded all patients who had repeat endoscopies within one month of the previous endoscopy.

Data were collected from the endoscopy records on demographics (age sex and tribe), history of upper gastrointestinal bleeding and endoscopic findings. The information obtained from the endoscopy records was cross checked with the main hospital records to prevent errors in recording. Hemodynamic stability and resuscitation was performed by the various units before endoscopy. Biopsy was taken from suspicious lesions where necessary.

Data was collected using questionnaires and entered on Epi info 7. Statistical data analysis was performed with chi-square. Statistical significance was determined at $\mathrm{P}<0.05$. Information obtained from these patients were then recorded according to age, gender and endoscopic findings and presented inform of tables.

The study was approved by the department of surgery and the Ethical Research Committee of Lacor Hospital.

\section{Results}

A total of 3357 patients underwent upper gastrointestinal endoscopy during the five-year period covered in the study between January 2006 to December 2010. Out of the total number, 224 (6.67\%) patients had endoscopy because of UGIB which consisted of $113(50.4 \%)$ males and 111 $(49.6 \%)$ females, and the mean age was 42 years \pm SD 15.88. The male to female ratio was almost 1:1 (table 1).

Table 1: distribution of patients with UGIB according to age and sex

\begin{tabular}{|c|c|c|c|c|c|c|c|}
\hline Age (years) & \multicolumn{2}{|c|}{$10-20$} & \multicolumn{2}{|c|}{$21-30$} & \multicolumn{2}{|c|}{$31-40$} & \multirow[t]{2}{*}{$36(16.1)$} \\
\hline Total & & & 113 & & 224 & & \\
\hline Male & 7 & 25 & 34 & 23 & 17 & 7 & $113(50.4)$ \\
\hline Total & 13 & 44 & 60 & 44 & 34 & 29 & $224(100)$ \\
\hline
\end{tabular}

Mean age $=42.9$ years \pm SD 15.88

The commonest cause of UGIB according to endoscopic findings was esophageal varices consisting of $40.6 \%$ with male to female ration of almost 2:1, followed by esophagitis $(14.7 \%)$ with almost equal frequency in either sex. Gastritis and peptic ulcer disease (duodenal and gastric ulcers) were $12.9 \%$ and 6.2 respectively. The malignant conditions (gastric and esophageal cancers) contributed to $2.6 \%$ with male to female ratio of $2: 1$. Other less frequent causes of UGIB were hiatus hernia (1.8), duodenitis ( $0.9 \%)$, others-gastric polyp $(0.4 \%)$. Normal endoscopic finding was $16.1 \%$ in patients who had UGIB (table2).

Table 2: Distribution of endoscopic findings and its frequency with sex

\begin{tabular}{llll}
\hline Endoscopy findings & Number of females (\%) & Number of males (\%) & Total (\%) \\
\hline Esophageal varices & $34(15.2)$ & $57(25.4)$ & $91(40.6)$ \\
Esophagitis & $19(8.5)$ & $14(6.3)$ & $33(14.7)$ \\
Gastritis & $16(7.1)$ & $13(5.8)$ & $29(12.9)$ \\
Duodenal ulcer & $3(1.3)$ & $6(2.7)$ & $9(4)$ \\
Gastroduodenitis & $3(1.3)$ & $5(2.2)$ & $8(3.6)$ \\
Gastric ulcer & $4(1.8)$ & $1(0.4)$ & $5(2.2)$ \\
Hiatus hernia & $4(1.8)$ & 0 & $4(1.8)$ \\
Cancer stomach & $1(0.4)$ & $2(0.9)$ & $3(1.3)$ \\
Cancer esophagus & $1(0.4)$ & $2(0.9)$ & $3(1.3)$ \\
Duodenitis & $1(0.4)$ & $1(0.4)$ & $2(0.9)$ \\
Gastric polyp & $1(0.4)$ & 0 & $1(0.4)$ \\
Normal & $24(10.7)$ & $12(5.4)$ & \\
\hline
\end{tabular}

* Peptic ulcer disease (duodenal ulcer and gastric ulcer) in total is $6.2 \%$, mErosive mucosal disease( esophagitis, gastritis and gastroduodenitis)contributed 31.2\% 


\section{Discussion}

This study found that, the mean age of the patients who had UGIB was 42.9 years \pm SD 15.88 and this is similar to other studies reported in Africa. ${ }^{7,8}$. However this is lower than the age reported in the developed world and could just be a reflection of the generally older population of the west. The overall male to female proportion of patients presenting with UGIB was nearly the same as compared to what was reported in other studies 9, 10. This could be explained by the endemic nature of hepatitis B infection and schistosomiasis among the population in northern Uganda in nearly equal ratio of male to female ${ }^{11}$.

Esophageal varices was the commonest cause of UGIB accounting for $40.6 \%$ of all patients with male to female ratio of approximately 2:1. This is similar to studies conducted in the developing world especially in the African countries which have reported esophageal varices as the major cause of $\mathrm{UGIB}^{7,8,12,13}$. but contrary to the findings of most western studies where peptic ulcer disease has been identified as the commonest cause of UGIB ${ }^{5,6,8,9}$. This discrepancy may be because of the high prevalence of chronic liver disease as a result of the endemic nature of hepatitis $B$ infection and schistosomiasis in northern part of Uganda and other African countries. However this could have been evident if hepatitis B infection was tested and evidence of portal fibrosis found in these patients

Erosive mucosal disease (esophagitis, gastritis and duodenitis and gastroduodenitis) was the second cause of UGIB which accounted for $23.7 \%$ of cases with esophagitis being the commonest representing $14.7 \%$, followed by gastritis $12.9 \%$ of all cases of UGIB. Though UGIB in a patient may have multiple etiologies, in this study only $3.6 \%$ had both gastritis and duodenitis but the auhors preferred to write the diagnosisas gastroduodenitis. These findings are similar to those reported from both the western world (Europe, South America) and Africa ${ }^{10,13,14}$.

The peptic ulcer disease which has been reported as the most common cause of UGIB mainly in the west ${ }^{3,10,12,15,16}$ was the third commonest cause in this study, accounting for only $6.2 \%$, though with duodenal ulcer (4\%) being more common than gastric ulcer $(2.2 \%)$. This is similar to many studies reported.

Other less common causes were esophageal carcinoma (1.3\%), gastric cancer $(1.3 \%)$, hiatus hernia $(1.8 \%)$. Esophageal carcinoma was reported in one study from Afghanistan been the commonest cause of UGIB, probably because of the highest incidence of esophageal cancer from the Iran-China belt ${ }^{17}$.

No source of bleeding was found in $16.1 \%$ of the patients. This is similar to studies reported from Africa and India $7,8,18$. and higher than the figures reported from the western world ${ }^{10}$. This is probably explained by the fact that patients in the western world tend to have endoscopy earlier following UGIB than in most developing world. In this study it was noted that endoscopy was done on average after 72 hours and usually mucosal lesions are well known to heal quickly and so the time interval between the bleeding episode and endoscopy influences endoscopic diagnosis.

Limitations of the study included the fact that most patients had endoscopy done after 72 hours of initial episode of bleeding, and it's well known that mucosal lesions heal quickly, so as a result a big percent of patients had no source of bleeding identified. The different surgeons though experienced in endoscopy may to some extend have an observer variation. Also the fact that the endoscopy was done under lignocaine guggle, some patients did not tolerant the scope well and hence some lesions may have been missed.

\section{Conclusion}

Oesophageal varices are the commonest cause of upper gastrointestinal bleeding in this environment probably due to the high endemic nature of hepatitis $B$ infection and schistosomiasis among the population in northern Uganda compared to the west which is mainly peptic ulcer disease.

\section{References}

1. Gralnek IM, Jensen MD, Gornbein J, et al Clinical and economic outcomes of patients with severe peptic ulcer hemorrhage and non bleeding visible vessels: An analysis of two prospective clinical trials: Am J Gastrointerol 1998: 93:20472056

2. Fallah MA, Prakash C, Edmundowicz S. Acute gastrointestinal bleeding. Med Clin North Am. Sep 2000;84(5):1183 -208.

3. Jutabha R, Jensen MD. Management of upper gastrointestinal bleeding in patients with chronic liver disease. Med Clin North Am 1996; 80(5); 1035 $-1068$.

4. Baradarian R, Ramdhaney S, Chapalamadugu R, Skoczylas L, Wang K, Rivilis S, et al. Early intensive resuscitation of patients with upper gastrointestinal 
bleeding decreases mortality. Am J Gastroenterol. Apr 2004;99(4):619 -22. [

5. Yachimski PS, Friedman LS. Gastrointestinal bleeding in the elderly. Nat Clin Pract Gastroenterol Hepatol. 2008;5(2):80-93.

6. Adang RP, Vismans JF, Talmon JL et al. Appropriateness of. A14-A14. indications for diagnostic upper gastrointestinal endoscopy: Association with relevant endoscopic diseases. Gastroint Endosc 1995; 42(5);390 -397.

7. Van Leerdam ME. Epidermiology of acute uppergastrointestinal bleeding: Best practice research clinical gastroenterology 2008; 22:209-224.

8. Mwanahawa S, Segni M, Charles M et al.The etiology, management and clinical outcome of upper gastrointestinal bleeding among patients admitted at the Kilimanjaro Christian Medical Centre in Moshi, Tanzania. Tanzania journal of Health Research 2010;12 (4):304-308.

9. Cook DJ, Guyatt GH, Salena BJ, Laine LA. Endoscopic therapy for non-variceal upper gastrointestinal haemorrhage: a meta-analysis. Gastroenterology 1992; 102: 139-48

10. Rockall TA, Logan RF, Devlin HB, Northfield TC. Incidence and mortality from acute upper gastrointestinal haemorrhage in the United Kingdom. Br Med J 1995; 311: 222-6 .

11. Josephine B, Fiona B, Makumbi I et al. HepatitisB infection highly endemic in Uganda: findings from a national serosurvey. Br.Med J 1995;311:221-6 .

12. Malu AO, Wali SS, Kazmi R, Macaulay D, Fakunlay YM. Upper GI endoscopy in Zaria,
Northern Nigeria. West Afr J Med. 1990; 9: 27984 .

13. Pruthi HS, Sharma SK, Singh B, Anand AC. Aetiology of upper gastrointestinal bleeding: an endoscopic study. MJAFI 2000; 56: 188-191

14. Zaltman C, de Souza, HSP, Castro MEC, Sobral MFS, Dias PCP, Lemos V. Upper gastrointestinal bleeding in a Brazilian Hospital: a retrospective study of endoscopic records 2002; 39:74-80

15. Gostout CJ, Wang KK, Ahlquist DA, Clain JE, Hughes RW, Larson MV, Petersen BT, Shroeder KW, Tremaine WJ, Vigianno TR. Acute gastrointestinal bleeding. Experience of a specialised management team. J Clin Gastroenterol 1992; 14: 260-7.

16. Morgan AG, MacAdam WA, Walmsley GL, Jessop A, Horrocks JC, de Dombal FT. Clinicalfindings, early endoscopy and multivariate analysis in patients bleeding from the upper gastrointestinal tract. Br Med J. 1985; 291(6495): $237-40$

17. Imad G, Samir O, Youef A. Upper astrointestinal endoscopy in Jordanian field Hospita in Afghaniatan. JRMS De 2004; 11(2):62 -64.

18. Kelly P, katerna M, Amadi B, Zimba L, Aparico S, Mudenda K, Baboo K, Zulu I. Gastrointestinal pathology in the University Teaching Hospital, Lusaka, Zambia: review of endoscopic and pathology records. Trans Royal Soc Trop Hyg 2008; 102: 194-99 